\title{
Revisão: Fundamentos e materiais para o projeto da microestrutura de isolantes térmicos refratários de alto desempenho
}

\section{(Review: Fundamentals and materials for the microstructure design of high performance refractory thermal insulating)}

\author{
D. O. Vivaldini, A.A.C. Mourão, V.R. Salvini, V.C.Pandolfelli \\ Departamento de Engenharia de Materiais, Universidade Federal de S. Carlos, Rod. Washington Luiz km 235 \\ S. Carlos, SP, Brasil 13565-905 \\ vicpando@ufscar.br
}

\begin{abstract}
Resumo
A eficiência energética de isolantes térmicos cerâmicos que são utilizados em altas temperaturas é definida pela condutividade térmica $(\mathrm{K})$ do material. Os mecanismos básicos de transferência de calor, que são a condução, a radiação e a convecção são neste texto relacionados com os principais parâmetros microestruturais de interesse visando à obtenção de isolantes térmicos com valores de condutividade térmica adequados para o uso em uma ampla faixa de temperatura. Pôde-se concluir que a condutividade térmica de cerâmicas porosas é função da composição e microestrutura da porção sólida do material. Além disso, a porosidade total e o tamanho de poros são variáveis fundamentais, sendo que quanto maior a fração volumétrica de poros menor a condutividade térmica. Mostrou-se que poros com tamanho entre 0,5 e $4 \mu \mathrm{m}$ são os mais eficazes para a redução de $\mathrm{K}$, devido à menor permeabilidade e elevada capacidade de espalhamento conferida à microestrutura. Também foi possível concluir que a presença de materiais opacificadores pode reduzir significativamente a contribuição da radiação, fato que pôde ser observado por meio das teorias de acoplamento entre condução e radiação, uma vez que tais materiais aumentam a espessura ótica dos isolantes. Por fim, realizouse um estudo sobre os principais tipos de isolantes cerâmicos comerciais e as características microestruturais que conferem suas propriedades.
\end{abstract}

Palavras-chave: economia de energia, isolantes térmicos.

\begin{abstract}
The energy efficiency of ceramic thermal insulating used at high temperatures is mainly associated to the thermal conductivity (K) of the material. The basic mechanisms of heat transfer, which are conduction, radiation and convection, are in this text, related with the main microstructural parameters aiming to attain thermal insulating with suitable thermal conductivity values in a wide temperature range. It was possible to conclude that the thermal conductivity of porous ceramics is a function of the solid fraction composition and its microstructure. Moreover, the porosity and the pore size are key variables, where the higher the pore volumetric fraction, the lower the thermal conductivity. It was also shown that pores with sizes in the range of 0.5 and $4 \mu \mathrm{m}$ are the most efficient towards the reduction of $K$, due to the lower permeability and high scattering capacity given to the microstructure. It is also stated that the presence of opacifier materials can significantly reduce the radiation, a fact that could be observed by the coupling theories involving conduction and radiation, as such materials increase the optical thickness of the insulating products. Finally, a study relating the main types of commercial ceramic insulating and their microstructural characteristics that lead to their usual characteristic properties was carried out.
\end{abstract}

Keywords: energy saving, thermal insulating.

\section{INTRODUÇÃO}

A vida humana sempre foi em grande parte definida pela disponibilidade energética e as grandes revoluções tecnológicas ocorridas ao longo da história estiveram muitas vezes vinculadas à descoberta e/ou implementação de novos tipos de energia. O século XX viu a transição da utilização do carvão para a ascensão do petróleo e do gás natural. O século XXI não será diferente, pois à medida que a disponibilidade de combustíveis fósseis for diminuindo e os custos de utilização dessas matérias-primas se elevarem, novas tecnologias serão introduzidas para atender a demanda crescente. Entretanto, especialistas sugerem que essa transição para novas fontes energéticas (solar, eólica, etc.) não será rápida, mas poderá levar décadas para ocorrer [1]. Nesse ínterim, o desafio iminente é atender a demanda energética, que continuará a ser crescente [2]. Sendo assim, a melhor rota será aumentar a eficiência, isto é, gastar menos para realizar a mesma quantidade de trabalho ou realizar mais trabalho usando a mesma quantidade de energia. $\mathrm{O}$ aumento de eficiência não é uma tendência recente, esse fenômeno vem ocorrendo desde a década de 70, após o primeiro choque do petróleo. Este processo se deu principalmente no setor de equipamentos industriais e no segmento de transportes 
(caminhões, carros, etc.). A tendência é que este processo continue e se intensifique [2].

Vários estudos relacionam a reutilização e conservação de calor como elemento fundamental para elevação da eficiência energética em processos industriais $[3,4]$. Outros elementos também se mostram importantes como a elevação do rendimento de motores e bombas elétricas, entretanto a redução de energia consumida em processos que envolvam calor (secagem, calcinação, tratamentos térmicos, etc.), especialmente aquelas onde as temperaturas são moderadas ou altas, pode promover reduções significativas de consumo energético. Muitas das soluções propostas por estes estudos apontam para a reutilização de calor, por exemplo, aquele que foi gerado em excesso em um processo para manutenção de outros paralelos. Todas as soluções apontam para conservação de calor em processos industriais. Para implementar este tipo de aumento de eficiência, o principal fator a ser melhorado é a eficiência inerente do isolamento térmico desses processos que é função das propriedades físicas dos materiais usados.

O foco do presente trabalho é situar a comunidade quanto à atual tecnologia de materiais para isolamento térmico por meio da revisão dos mecanismos básicos que governam a principal propriedade física a ser considerada na utilização desses materiais, a condutividade térmica $\mathrm{K}$. Isto se deve ao fato que este parâmetro define o fluxo de energia através de um material que é aquecido em uma de suas faces e, dessa forma, quanto menor a condutividade, menor o fluxo através do material, o que reduz a quantidade de energia que está deixando o sistema.

Para processos que operam acima de $150{ }^{\circ} \mathrm{C}$ os únicos materiais disponíveis e que possuem as maiores eficiências de isolamento são os cerâmicos, por dois principais motivos: a baixa condutividade térmica desses materiais, em relação aos metais, e sua alta estabilidade térmica, quando comparada aos polímeros. Em temperaturas abaixo de 150 ${ }^{\circ} \mathrm{C}$, especialmente na faixa próxima à temperatura ambiente, os materiais cerâmicos concorrem com os polímeros e materiais naturais, como a cortiça. Entretanto, os processos que demandam grandes quantidades de energia térmica são aqueles que ocorrem em altas temperaturas $\left(>800{ }^{\circ} \mathrm{C}\right) \mathrm{e}$ para os quais o aumento da eficiência do isolamento térmico promoveria maiores reduções de gasto energético.

Foi mostrado que a condutividade térmica dos materiais é o único fator de seleção (no que concerne o desempenho térmico) para isolantes térmicos que operam em processos contínuos e o principal fator para processos que operam de forma intermitente [5]. Para este último caso, o critério de seleção torna-se o produto da condutividade térmica $\mathrm{K}$, da capacidade calorífica $\mathrm{C}$ e da densidade do material @. Essas três propriedades físicas $(\mathrm{K}, \mathrm{C}$ e $\mathrm{Q})$ são reduzidas com a introdução de porosidade no material, causando um enorme efeito no comportamento térmico.

O estudo da influência de diversos parâmetros sobre as propriedades térmicas dos materiais cerâmicos foi e ainda é alvo de intenso estudo pela comunidade acadêmica e muitos modelos foram propostos para analisar o comportamento da condutividade térmica dos materiais cerâmicos [6-8]. Os principais e mais relevantes dentre esses serão apresentados e discutidos no presente trabalho.

O processo de transferência de energia térmica através dos materiais é função da somatória de vários subprocessos, sendo os principais a condução e a radiação. Quando a permeabilidade da estrutura é alta, a convecção de gás dentro do material também pode contribuir significativamente $[8,9]$.

\section{Condução}

Este processo ocorre quando quanta de energia térmica são conduzidas por meio das vibrações de vários átomos em relação à sua posição de equilíbrio. Para todos os materiais esse mecanismo ocorre por meio de fônons e também por elétrons livres, este último no caso de materiais metálicos e alguns tipos de semicondutores.

Fônons são vibrações atômicas ordenadas que ao se propagarem através do material, transferem energia de um ponto a outro, como no caso de regiões mais quentes, onde a concentração de fônons é maior, às mais frias. Para cerâmicas refratárias, o processo de condução é efetuado exclusivamente por fônons, uma vez que nesses materiais não há elétrons livres. A condução por fônons pode ser descrita pela equação A [10]:

$$
\mathrm{K}=\frac{1}{3} \int \text { C.v. } \tau \mathrm{d} \omega
$$

na qual C é a capacidade calorífica específica (J/kg.K), v a velocidade média de propagação dos fônons $(\mathrm{m} / \mathrm{s}), \tau$ o tempo de relaxação dos fônons e $\omega$ a frequiência de vibração dos fônons. Tanto a velocidade média de propagação (v), quanto o tempo de relaxação $\tau$ são função da freqüência de vibração $\omega$.

O tempo de relaxação $\tau$ é proporcional ao livre caminho médio dos fônons $(\zeta)$. Já o livre caminho médio $(\zeta)$ dos fônons é uma função da temperatura, sendo que à medida que esta aumenta, o livre caminho médio é diminuído. Este fenômeno é verificado porque com a elevação da temperatura, passam a ocorrer interações entre os fônons, as quais acabam dificultando sua propagação. Este efeito é conhecido por Umklapp [10]. Dessa maneira, com a elevação da temperatura, a condutividade térmica por fônons do material diminui continuamente, pois o livre caminho médio é sempre reduzido.

A Fig. 1 apresenta a condutividade térmica em função da temperatura para algumas matérias-primas cerâmicas refratárias. Como pode ser observada, com a elevação da temperatura a condutividade térmica diminui, devido à redução do livre caminho médio dos fônons.

Os valores de condutividade observados para a alumina, mulita e magnésia são elevados, pois são para materiais completamente densos, isto é, sem porosidade. Nesta figura também pode ser observado o hexaluminato de cálcio $\left(\mathrm{CA}_{6}\right)$, o qual possui porosidade elevada, e por isso, condutividade térmica muito menor do que os materiais densos, entretanto em temperaturas menores do que aquelas mostradas na 


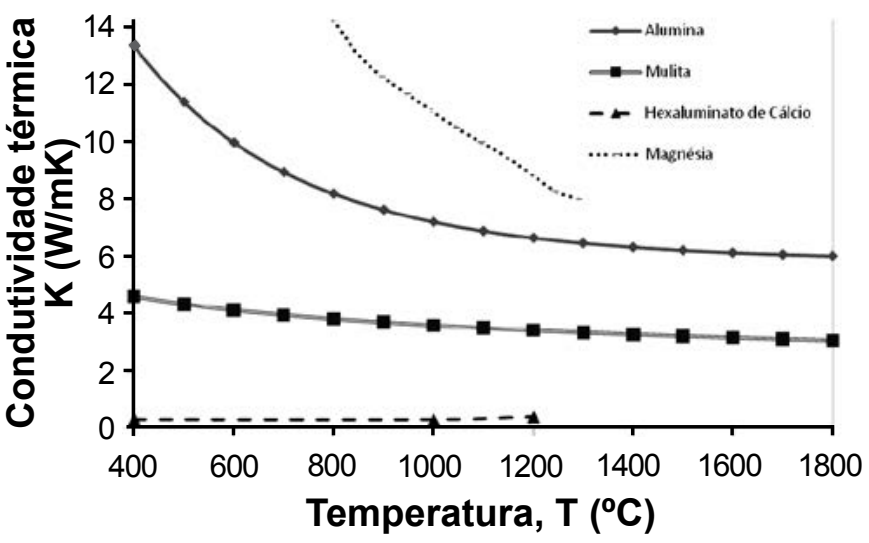

Figura 1: Condutividade térmica de cerâmicas em função da temperatura [24, 37, 39].

[Figure 1: Thermal conductivity of ceramics as a function of temperature $[24,37,39]$.]

Fig. 1, a condutividade desse material também apresenta valores superiores e decai com a elevação da temperatura, uma vez que os fônons também são atuantes na porção sólida desse material.

A condução de um material pode ser reduzida, em altas temperaturas $\left(>1000^{\circ} \mathrm{C}\right)$, por meio da introdução de poros, os quais contêm gás de baixa condutividade, e assim contribuem para a redução da condução de calor através do material. Além disso, a presença de macro e microtrincas também reduzem a condutividade, uma vez que estas são descontinuidades da matriz sólida. Também é observado que a condutividade térmica é função da natureza do contato entre as partículas sólidas, por exemplo: a condutividade térmica de um corpo sinterizado e de um arranjo de partículas aglomeradas tende a ser distinto, mesmo que a porosidade seja mantida, pois o contato entre as partículas aglomeradas é menor do que em um corpo sinterizado [8]. Já o efeito do microtrincamento entre grãos de fases que possuem coeficientes de expansão consideravelmente diferentes sobre a condutividade térmica pode ser observado no sistema alumina-mulita e em vários outros [6].

A redução da condutividade de um sólido por meio da introdução de poros foi alvo de intenso interesse nas ultimas décadas e diversos modelos foram propostos para analisar a questão [7]. A redução da condutividade do material depende da fração volumétrica total de poros, bem como de seu formato. Para poros esféricos e uniformemente distribuídos no material, os quais estão totalmente separados pela matriz, a equação de Maxwell [6] pode ser aplicada:

$$
\mathrm{K}_{\text {cond }}=\frac{(1-\mathrm{P}) \cdot \mathrm{K}_{\text {sólido }}}{1+0,5 \mathrm{P}}
$$

na qual P é a porosidade do material (\%) e $\mathrm{K}_{\text {sólido }}(\mathrm{W} / \mathrm{mK})$ a condutividade térmica do material denso.

Entretanto,os poros presentes emum material dificilmente se acham completamente isolados uns dos outros, havendo conexões entre eles. Esse tipo de interação não é descrito pela teoria de Maxwell, de forma que outros modelos foram desenvolvidos para melhor descrever o comportamento real de materiais porosos. Extensas revisões foram feitas sobre o assunto [7,11]. Um avanço nesta direção foi o modelo proposto [8], que leva em consideração a presença de defeitos extras na microestrutura do material, como por exemplo, macro e micro trincas. Esse fato explica a relação entre a resistência mecânica e a condutividade térmica de materiais cerâmicos, mantida a mesma porosidade aparente. A equação $C$ descreve a variação da condutividade térmica com a porosidade segundo o modelo de Litovsky.

$$
\mathrm{K}_{\text {cond }}=\mathrm{K}_{\text {solido }} \cdot \mathrm{M} \cdot(1-\mathrm{P})^{\frac{2}{3}}
$$

sendo $\mathrm{K}_{\text {cond }}$ a condutividade efetiva devido à condução, $\mathrm{K}_{\text {sólido }}$ a condutividade do material totalmente denso e M é um fator que contabiliza a resistência térmica devido ao contato entre as partículas que compõem o material. Este parâmetro varia entre zero e um e é adimensional. Quanto pior for o contato entre as partículas, menor é o valor de $\mathrm{M}$.

$\mathrm{O}$ processo de condução também ocorre no gás, isto é, através das colisões entre suas moléculas e, assim, contribuem para a transmissão de energia térmica. Este efeito ocorre dentro de cada poro e está associado ao livre caminho médio das moléculas do gás que é uma função da temperatura, da pressão e do tipo de gás, como pode ser observado na equação D para o ar [12] :

$$
1_{\text {gás }}=\frac{0,2 \cdot \mathrm{T}}{\mathrm{A}}
$$

sendo $1_{\text {gás }}$ o caminho livre médio entre colisões das moléculas do ar (nm), T a temperatura absoluta (K) e A a pressão (atm).

Por meio da equação D pode-se estimar o livre caminho médio das moléculas de gás nas temperaturas em que os isolantes são utilizados. Sendo assim, a condutividade do gás é função do tamanho do poro e também da relação entre o tamanho do poro e o livre caminho médio das moléculas de gás. Na equação B, o efeito do tipo do gás está embutido na constante que multiplica a equação, que nesse caso para o ar é 0,2 . Entretanto este valor será alterado caso o tipo de gás mude.

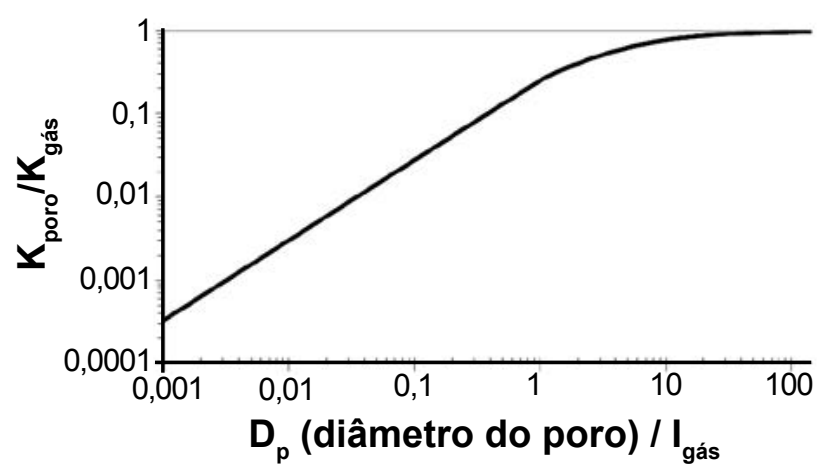

Figura 2: Condutividade relativa do gás em função da relação entre o tamanho do poro e o livre caminho médio do gás $\left(1_{\text {gás }}\right)$ [12].

[Figure 2: Relative conductivity of gas versus the ratio between the size of the pore and the mean free path of the gas $\left(l_{\text {gás }}\right)$ [12].] 
A Fig. 2 mostra a relação entre a condutividade do gás no poro pela condutividade do gás livre $\left(\mathrm{K}_{\text {poro }} / \mathrm{K}_{\text {gás }}\right)$ em função da relação entre o tamanho do poro $\mathrm{D}_{\mathrm{p}}$ e o livre caminho médio para condução do gás $1_{\text {gás }}$. Quando o tamanho do poro se aproxima das dimensões de $1_{\text {gás }}$, a condutividade do gás decai rapidamente dentro dos poros.

A condutividade do ar é apresentada em função da temperatura na Fig. 3 [13]. Como pode ser observado, acima de $1500^{\circ} \mathrm{C}$ a contribuição para a condutividade total do material dada pela condução através do gás é superior a $0,1 \mathrm{~W} / \mathrm{m} . \mathrm{K}$. Tal contribuição pode ser significativa no caso de isolantes porosos, nos quais valores adequados de condutividade podem ser considerados abaixo de 0,4 $\mathrm{W} / \mathrm{m}$.K. Portanto, a redução de $0,1 \mathrm{~W} / \mathrm{m} . \mathrm{K}$ representaria $25 \%$ de redução na condutividade térmica total. É devido a este fato que trincas em contornos de grão podem diminuir a condutividade de cerâmicas, pois a distância entre as faces da trinca podem ser da ordem de tamanho do $1_{\text {gás }}[14]$.

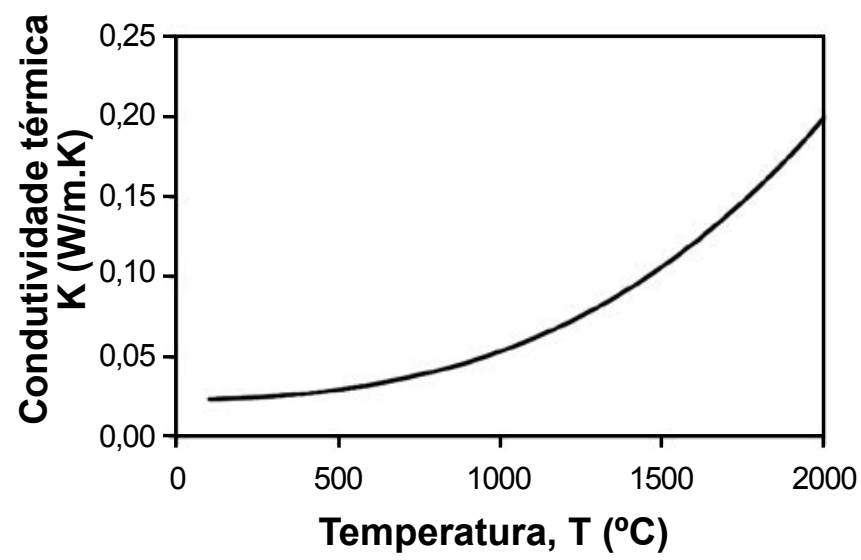

Figura 3: Condutividade térmica do ar em função da temperatura [13].

[Figure 3: Air Thermal conductivity of air as a function of temperature [13].]

Portanto, para que a contribuição da condução seja minimizada, a porosidade deve ser a maior possível, para que haja a menor quantidade de fração sólida. Além disso, o tamanho dos poros deve ser menor do que o livre caminho médio de condução do gás na temperatura de trabalho. Caso estes dois requisitos sejam cumpridos, isolantes que possuem condutividades térmicas menores do que a do ar podem ser obtidos, fato que pode ser observado em aerogéis [15].

\section{Radiação}

O processo de transferência térmica por radiação ocorre por meio da propagação, absorção e emissão de fótons. Quando a radiação eletromagnética atinge a superfície de um material, ela pode ser refletida, transmitida ou absorvida. Do ponto de visto macroscópico e no que concerne a permanência de energia em um sistema em equilíbrio, o único fator a ser considerado é a fração de energia transmitida. Quanto maior esta for maior será o fluxo de energia através do material e, portanto, maior será a condutividade térmica. Nesse contexto, a natureza e intensidade da radiação que os materiais emitem são de fundamental importância para entender o papel da microestrutura do material e sua influência no processo de transferência térmica por radiação.

A radiação eletromagnética que é emitida de materiais é função da temperatura e é descrita pelo espectro de emissão de corpo negro, desenvolvido por Max Planck [16] e apresentado na equação E:

$$
\mathrm{B}(\mathrm{T})=\frac{2 \mathrm{~h} v^{3}}{\mathrm{c}^{2}} \cdot \frac{1}{\mathrm{e}^{\left(\frac{\mathrm{h} v}{\mathrm{~K}_{\mathrm{B}}}\right)}-1}
$$

sendo $\mathrm{h}$ a constante de Planck (J.s), $v$ a frequência do fóton $(\mathrm{Hz})$, c a velocidade de propagação da luz $(\mathrm{m} / \mathrm{s}), \mathrm{K}_{\mathrm{B}}$ a constante de Boltzmann $(\mathrm{J} / \mathrm{K})$ e $\mathrm{T}$ a temperatura absoluta (K). Esta faixa de radiação eletromagnética é chamada radiação térmica.

A Fig. 4 apresenta o espectro de radiação eletromagnético em função do comprimento de onda $\lambda$. A radiação térmica emitida por materiais nas temperaturas observadas nos processos industriais encontra-se, em sua maior parte, na faixa do infravermelho, a qual possui comprimentos de onda que variam entre 100 e aproximadamente $1 \mu \mathrm{m}$.

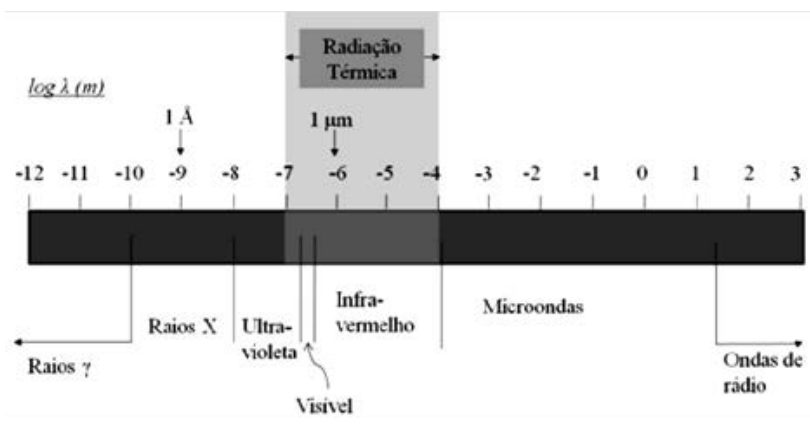

Figura 4: Espectro de radiação eletromagnética [16, 17].

[Figure 4: Electromagnetic radiation spectrum [16, 17].]

A equação E mostra que cada temperatura está associada à um espectro de emissão de fótons. A equação de Planck é válida apenas para um caso idealizado, pois, na realidade os materiais emitem menos do que descrito por Planck. A relação entre a quantidade de energia emitida pelo material e a quantidade de energia descrita pela equação E é a emissividade $\varepsilon$ deste. A Fig. 5 apresenta espectros de emissão de um corpo negro calculados pela equação de Planck para diversas temperaturas.

Por meio da Fig. 5 pode-se perceber que à medida que a temperatura é aumentada, a influência da radiação na condutividade térmica dos materiais tende a aumentar, pois a intensidade de radiação emitida cresce exponencialmente.

A condutividade térmica que será gerada entre as superfícies do material, isto é, entre a superfície onde a radiação incide (face quente) e a outra face (face fria) de um corpo é descrita pela equação $\mathrm{F}[7,8,11]$ : 


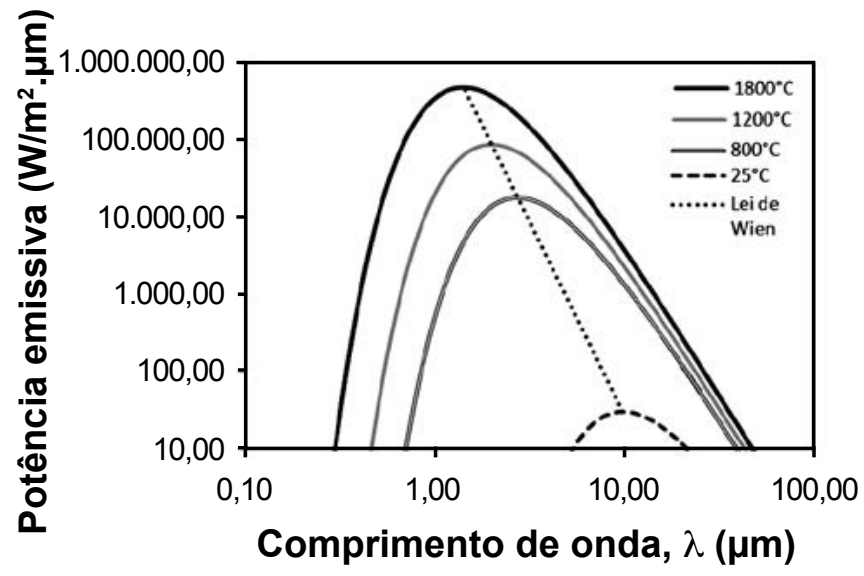

Figura 5: Espectro de potência emissiva de um corpo negro em diferentes temperaturas [17].

[Figure 5: Emissive power spectrum of a blackbody at different temperatures [17].]

$$
\mathrm{K}_{\mathrm{rad}}=\frac{16 \sigma \mathrm{n}^{2} \mathrm{~T}^{3}}{3 \beta^{*}}
$$

sendo $\sigma$ a constante de Stefan-Boltzmann $\left(\mathrm{W} / \mathrm{m}^{2} \mathrm{~K}^{4}\right)$, n é o índice de refração do material e $\mathrm{T}$ é a temperatura absoluta $(\mathrm{K})$. A variável $\beta^{*}$ na equação $\mathrm{F}$ é o coeficiente de extinção médio, o qual é função da capacidade de absorção e de espalhamento da radiação pela microestrutura do material, ou seja, é uma medida da capacidade do material e sua microestrutura interagirem com a radiação e impedirem sua transmissão através do material.

$O$ coeficiente de extinção médio $\beta *$ pode ser calculado por dois métodos:

Método de Rosseland [16]: mais adequado para materiais opacos, isto é, que possuam coeficiente de extinção espectral $\beta_{\text {ext }}$ elevados. Nesse método utiliza-se a convenção apresentada na equação G:

$$
\beta^{*}=\beta_{\mathrm{R}}
$$

sendo $\beta_{\mathrm{R}} \mathrm{o}$ coeficiente de extinção de Rosseland.

Método de Planck [18]: mais adequado para materiais transparentes, isto é, que possuem coeficiente de extinção espectral $\beta_{\text {ext }}$ baixos. Para este método utiliza-se a convenção apresentada na equação $\mathrm{H}$ :

$$
\beta^{*}=\mathrm{P}_{\mathrm{M}}
$$

na qual $\mathrm{P}_{\mathrm{M}}$ é o coeficiente de extinção de Planck. O cálculo destes coeficientes é apresentado em detalhes no Apêndice A.

$\mathrm{O}$ coeficiente de extinção médio $\beta^{*}$ está associado a outro parâmetro, o coeficiente de extinção espectral $\beta_{\text {ext }}$ (ver apêndice A), o qual é função do comprimento de onda $\lambda$ da radiação eletromagnética em questão. Este coeficiente, $\beta_{\text {ext }}$, é definido pela equação I:

$$
\beta_{\mathrm{ext}}(\lambda)=\beta_{\mathrm{a}}(\lambda)+\beta_{\mathrm{s}}(\lambda)
$$

na qual $\beta_{\mathrm{a}}$ e $\beta_{\mathrm{s}}$ são, respectivamente, os coeficientes de absorção e de espalhamento espectrais $\left(\mathrm{m}^{-1}\right)$, sendo estes função do comprimento de onda da radiação térmica.

A capacidade de absorção de radiação térmica de um material é descrita pelo coeficiente de absorção espectral $\beta_{\mathrm{a}}$, o qual é dado em unidade recíproca do metro $\left(\mathrm{m}^{-1}\right)$. Devido a isso se diz que o livre caminho médio do fóton é o inverso desse coeficiente, o que mostra que o primeiro é a espessura necessária de material para absorver o fóton. A fração de energia que é absorvida pelo material pode ser conduzida por meio de fônons e/ou reemitida novamente na forma de fótons. Novamente, essa fração reemitida pode ser absorvida, ou transmitida e assim sucessivamente, sendo que o processo de transferência térmica irá ocorrer por camadas.

Nos materiais cerâmicos, a radiação térmica é absorvida por meio de um mecanismo chamado de polarização iônica, no qual os íons presentes no material entram em ressonância com os fótons de infravermelho, os quais possuem frequência semelhante aquela de vibração da estrutura atômica do material . A Fig. 6 mostra uma comparação esquemática do coeficiente de absorção espectral para diversos materiais cerâmicos.

Ao observar as Figs. 5 e 6 pode-se notar um fenômeno muito importante: a contribuição da absorção $\left(\beta_{\mathrm{a}}\right)$, no cálculo do coeficiente de extinção $\beta_{\text {ext }}$, decai com a elevação da temperatura para os materiais cerâmicos refratários convencionais. Este fato não ocorre por que o espectro de coeficiente de absorção é alterado significativamente, mas porque o pico de emissão de radiação térmica desloca-se com o aumento da temperatura para comprimentos de onda onde a maioria dos óxidos refratários não absorve bem. $\mathrm{O}$ pico de emissão encontra-se em faixas onde o livre caminho do fóton no material é relativamente grande, o que eleva a condutividade térmica por radiação [6]. Portanto, em altas temperaturas, é o espalhamento e/ou a adição de materiais que absorvam melhor a radiação térmica que contribui significativamente para a extinção e, assim, para a redução da condutividade.

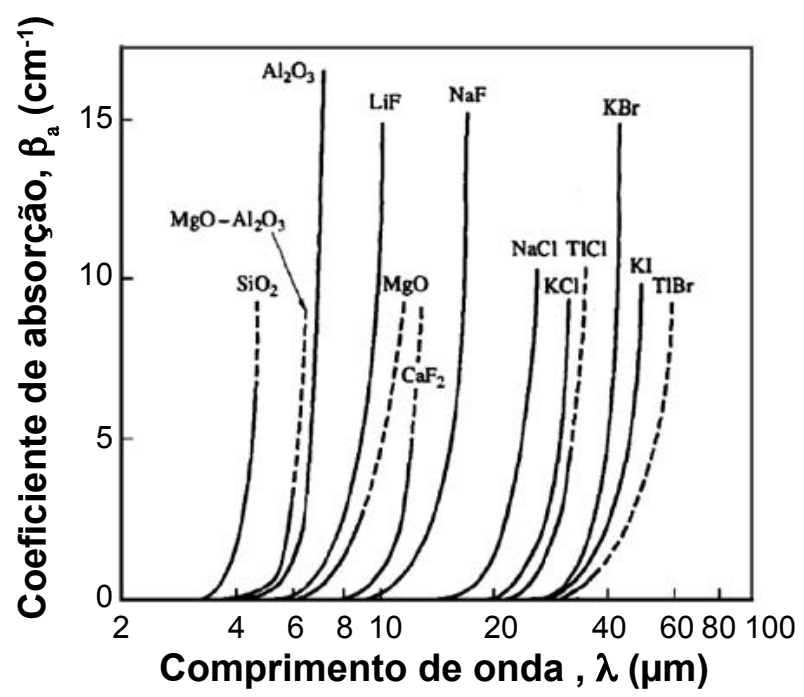

Figura 6: Coeficiente de absorção em função do comprimento de onda para diversos materiais cerâmicos (adaptado de [17]).

[Figure 6: Absorption coefficient as a function of wavelength for various ceramic materials (adapted from [17]).] 


\section{Superficie}

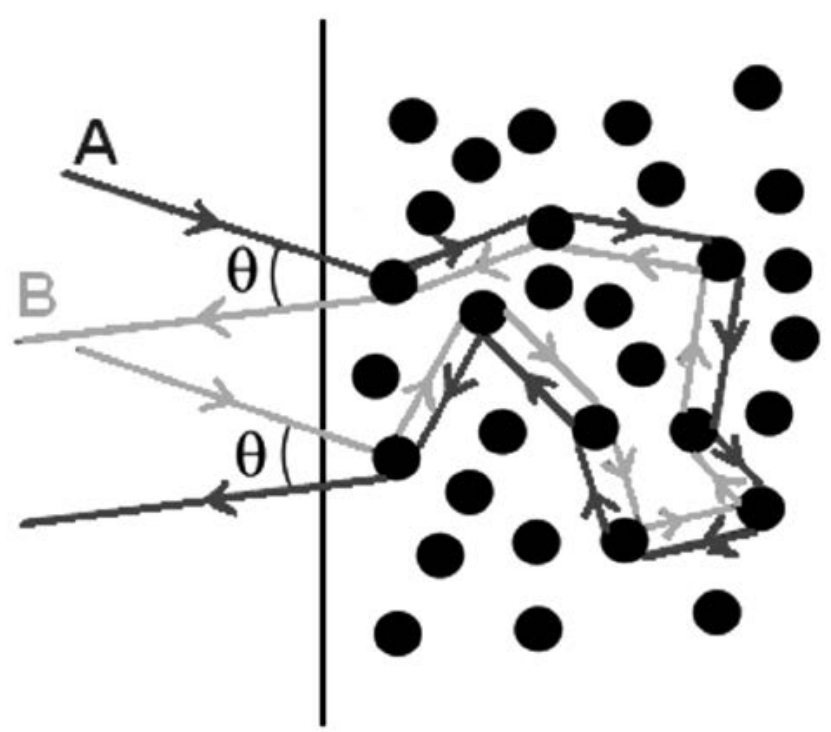

Figura 7: Esquema de retroespalhamento causado por poros ou partículas (círculos escuros) em dois feixes (A e B) de radiação incidentes na superfície de um material (adaptado de [19]).

[Figure 7: Backscattering effect sketch due to pores or particles (black circles) on two incident radiation beams ( $A$ and $B$ ) at the surface of a material (adapted from [19]).]

O espalhamento ocorre quando a presença de defeitos, vazios ou outras partículas desviam os fótons, sendo que estes podem ser em parte, direcionados para o sentido oposto ao de incidência da radiação. A Fig. 7 ilustra esse fenômeno, chamado de retroespalhamento.

A capacidade com que a microestrutura do material pode espalhar os fótons é função dos defeitos microestruturais presentes no material, entre eles poros e partículas de impurezas. O coeficiente espectral de espalhamento $\beta_{\mathrm{s}}$ é um parâmetro mais difícil de ser determinado do que o de absorção $\beta_{\mathrm{a}}$, uma vez que este depende da quantidade total e formato dos defeitos $[20,16]$.

O espalhamento causado por poros ou partículas dispersas na microestrutura pode ser compreendido por meio da equação $\mathrm{J}$ [21]:

$$
\beta_{\mathrm{s}}=\mathrm{Q}_{\mathrm{s}} \cdot \mathrm{N}_{\mathrm{s}} \cdot \pi \cdot \mathrm{r}_{\mathrm{s}}^{2}
$$

na qual $\mathrm{Q}_{\mathrm{s}}$ é a eficiência de espalhamento de um único defeito (poro ou partícula), $\mathrm{N}_{\mathrm{s}} \mathrm{o}$ número de defeitos (função da fração volumétrica de defeitos) que possui unidade recíproca de volume $\left(\mathrm{m}^{-3}\right)$ e $\mathrm{r}_{\mathrm{s}}$ é o raio do defeito.

O número de defeitos presentes, por unidade de volume, pode ser calculado por meio da equação K:

$$
\mathrm{N}_{\mathrm{s}}=\frac{\mathrm{P}}{\frac{4}{3} \cdot \pi \cdot \mathrm{r}_{\mathrm{s}}^{3}}
$$

sendo $\mathrm{P}$ a fração volumétrica de defeitos.

A eficiência de espalhamento $Q_{s}$ da radiação térmica é função de algumas variáveis, dentre elas uma das mais importantes é o parâmetro de tamanho $(\chi)$, o qual relaciona a dimensão de um vazio ou partícula em relação ao comprimento de onda $\lambda$ da radiação incidente, mostrado na equação L [11]:

$$
\chi=\frac{2 \pi \cdot r_{s}}{\lambda}
$$

sendo $\lambda$ o comprimento de onda do fóton. Entretanto o parâmetro $\mathrm{Q}_{\mathrm{s}}$ não é simples de ser calculado, pois sua relação com $\chi$ é bastante complexa.

Quando uma partícula é muito menor do que o $\lambda$ da radiação, $\chi$ assume valores muito pequenos, portanto a teoria de espalhamento de Rayleigh descreve o fenômeno. Por outro lado, quando a partícula ou vazio é muito maior do que $\lambda$, as leis da ótica geométrica melhor representam essa situação. Entretanto, quando possuem dimensões próximas a de $\lambda$, o espalhamento é descrito pela teoria de Mie [11].

A teoria de espalhamento de Mie leva em consideração o formato das partículas, o parâmetro de tamanho mencionado acima $\chi$ e o índice de refração complexo do material e da partícula ou vazio. Por meio de cálculos complexos podemse obter as eficiências de espalhamento $Q_{s}$ para diversos tamanhos de vazios ou partículas [17].

No caso de isolantes térmicos, o foco se dá sobre vazios, isto é, poros, uma vez não há sentido em colocar apenas partículas para espalhar a radiação sendo que estas não diminuem a condutividade do material sólido. Sendo assim, será investigado apenas o espalhamento atribuído a poros.

Como pode ser observado na Fig. 5, nas faixas de temperatura em que isolantes porosos cerâmicos são utilizados, $\left(500{ }^{\circ} \mathrm{C}\right.$ até $\left.\sim 1800{ }^{\circ} \mathrm{C}\right)$, o intervalo de comprimento de onda da radiação térmica de interesse encontra-se entre aproximadamente 1,4 e 3,7 $\mu \mathrm{m}$ [17], a qual se refere ao pico no espectro de emissão de materiais nessas faixas de temperatura. Estes valores podem ser obtidos utilizando a equação $\mathrm{M}$, chamada de lei de Wien, a qual calcula o comprimento de onda de maior emissão em uma determinada temperatura $\mathrm{T}(\mathrm{K})$, isto é, no pico de emissão [16]:

$$
\lambda_{\text {pico }}=\frac{2898}{T}
$$

Portanto, o espalhamento causado nesses comprimentos de onda é de vital importância para o processo de transferência térmica por radiação. Assim se a faixa de comprimentos de onda entre $1 \mu \mathrm{m}$ e $4 \mu \mathrm{m}$, for espalhada com alta eficiência, o material em questão se tornará um melhor isolante térmico para a faixa de temperatura de 500 e $1800{ }^{\circ} \mathrm{C}$.

Utilizando-se um algoritmo que resolve as equações propostas pela teoria de Mie, calculou-se o coeficiente de espalhamento $\beta_{\mathrm{s}}$, relacionado a poros esféricos de diversos tamanhos e em três materiais cerâmicos refratários [22].AFig. 8 apresenta o coeficiente de espalhamento, $\beta$ s, para alumina, mulita e sílica fundida. Nessa figura, o comprimento de onda da radiação incidente no poro foi mantido fixo em 1,5 $\mu \mathrm{m}$ 


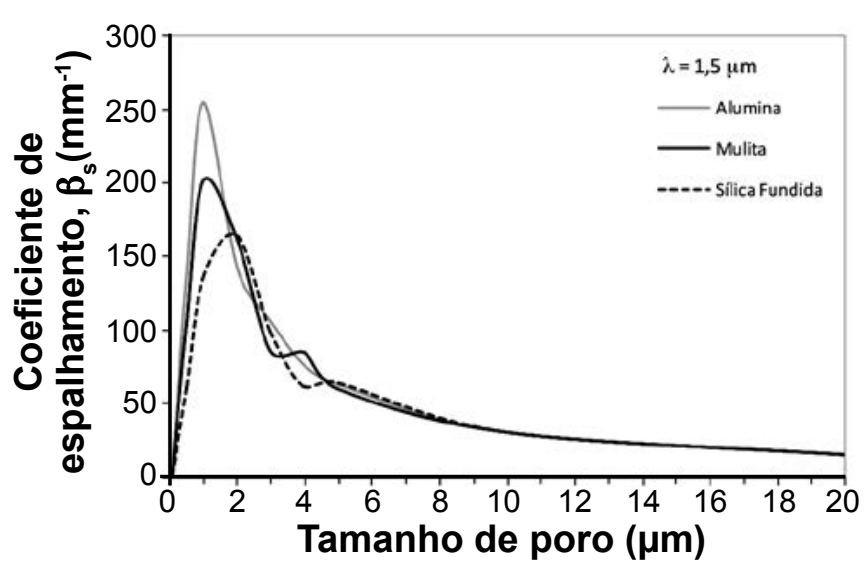

Figura 8: Coeficiente de espalhamento $\beta$ s para radiação com comprimento de onda $1,5 \mu \mathrm{m}$ em função do tamanho do poro para alguns materiais cerâmicos com $80 \%$ de porosidade.

[Figure 8: Relative scattering coefficient $\beta_{s}$ for the $1.5 \mu \mathrm{m}$ radiation wavelength as a function of pore size for different ceramic materials with $80 \%$ porosity.]

$\left(\mathrm{T}=1660{ }^{\circ} \mathrm{C}\right)$. Como pode ser observado, o coeficiente de espalhamento é maior para poros no intervalo $0,5 \mu \mathrm{m} \leq \beta_{\mathrm{s}} \leq$ $3 \mu \mathrm{m}$. Dessa forma, materiais que possuam poros nessa faixa serão melhores isolantes para alta temperatura.

A Fig. 9 possui as mesmas características da Fig. 8, entretanto o comprimento de onda da radiação incidente foi mantido constante em 3,5 $\mu \mathrm{m}$, correspondente ao pico de emissão na temperatura de aproximadamente $550^{\circ} \mathrm{C}$. Como pode ser observado, o diâmetro de poro necessário para causar maior espalhamento está entre 6 e $1 \mu \mathrm{m}$, independente do material em questão.

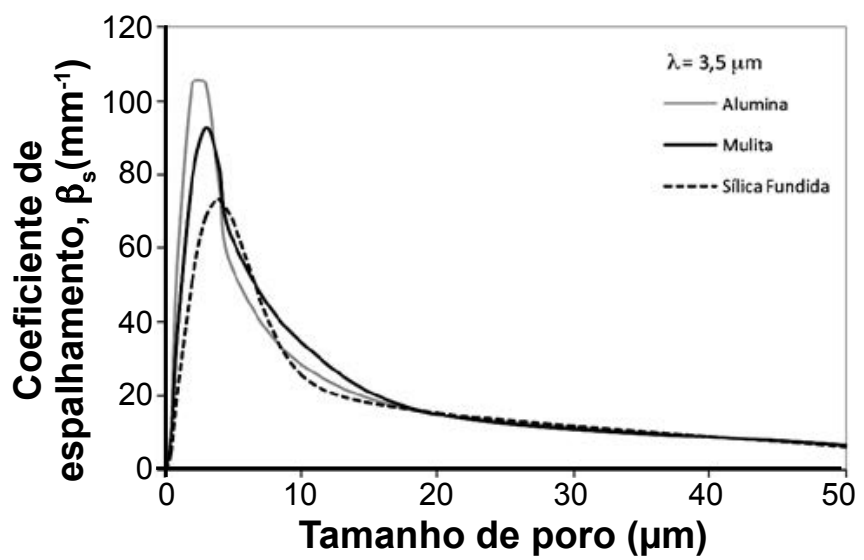

Figura 9: Coeficiente de espalhamento $\beta_{\mathrm{s}}$ para radiação com comprimento de onda $3,5 \mu \mathrm{m}$ em função do tamanho do poro para alguns materiais cerâmicos com $80 \%$ de porosidade.

[Figure 9: Relative scattering coefficient $\beta_{s}$ for $3.5 \mu \mathrm{m}$ radiation wavelength as a function of pore size for different ceramic materials with $80 \%$ porosity.]

A Fig. 10 mostra curvas de $\beta_{\mathrm{s}}$ para a alumina com $80 \%$ de porosidade, em função do comprimento de onda da radiação incidente sobre os poros e em função do diâmetro. Como pode ser observado, a faixa de diâmetro de poro para ocorrer maior espalhamento concentra-se entre 0,5 e $4 \mu \mathrm{m}$, para uma ampla faixa de temperaturas $\left(550\right.$ a $\left.1660{ }^{\circ} \mathrm{C}\right)$.

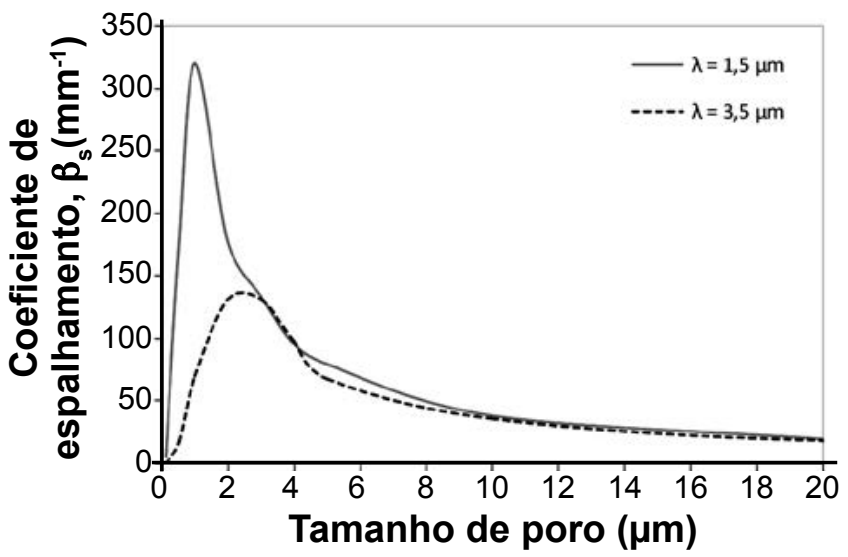

Figura 10: Coeficiente de espalhamento $\beta_{\mathrm{s}}$ para alumina em função do tamanho do poro para dois comprimentos de onda de radiação térmica, 1,5 e 3,5 $\mu \mathrm{m}$, referentes a temperaturas de $550{ }^{\circ} \mathrm{C}$ e $1650{ }^{\circ} \mathrm{C}$, respectivamente.

[Figure 10: Scattering coefficient $\beta$ s of alumina as a function of pore size and for two thermal radiation wavelengths, 1.5 and $3.5 \mu \mathrm{m}$ for $550{ }^{\circ} \mathrm{C}$ and $1650{ }^{\circ} \mathrm{C}$, respectively.]

Na Fig. 11 pode ser observada a dependência de $\beta_{\text {s }}$ com a porosidade total da alumina. Nesta figura, o coeficiente de espalhamento foi normalizado pela densidade da amostra, devido a isso $\beta_{\mathrm{s}}$ encontra-se em unidade de $\mathrm{m}^{2} \mathrm{Kg}^{-1}$. A dependência de $\beta_{\mathrm{s}}$ com a porosidade pode ser observada no parâmetro $\mathrm{N}_{\mathrm{s}}$ presente na equação J. Quanto maior a porosidade, maior é o valor de $\mathrm{N}_{\mathrm{s}}$. Conforme a Fig. 11, a porosidade possui grande influência sobre a capacidade de espalhamento da microestrutura, especialmente para poros abaixo de aproximadamente $10 \mu \mathrm{m}$.

Por meio de cálculos apresentados nas Figs. 8 a 11 é possível definir os tamanhos de poro mais eficazes no espalhamento da radiação térmica. Entretanto, como mostrado anteriormente (V. equação $G$ ), a absorção de fótons também é uma componente fundamental para a

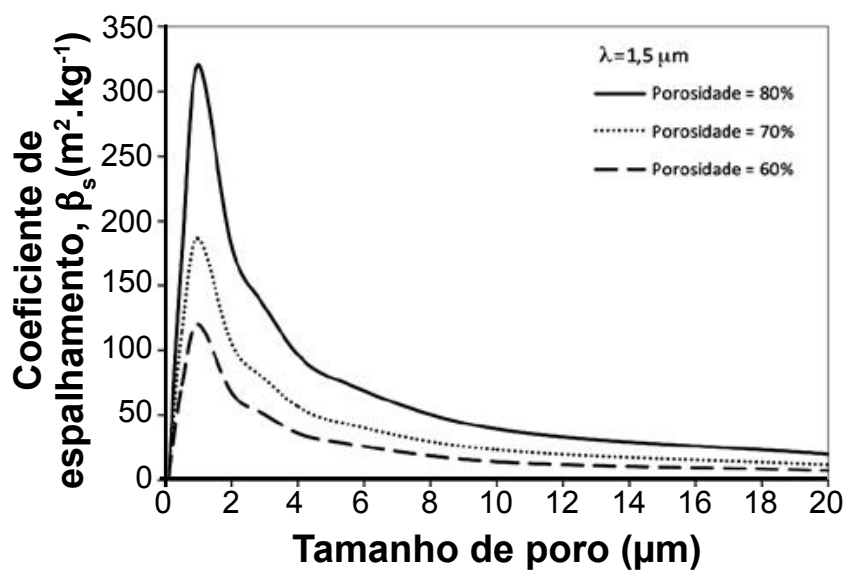

Figura 11: Coeficiente de espalhamento $\beta$ calculado para alumina, em função do diâmetro do poro e da porosidade (\%) para comprimento de onda de $1,5 \mu \mathrm{m}\left(1660^{\circ} \mathrm{C}\right)$.

[Figure 11: Scattering coefficient $\beta_{s}$ for alumina as a function of the pore diameter and the porosity (\%) for the $1.5 \mu \mathrm{m}$ radiation wavelength $\left.\left(1660^{\circ} \mathrm{C}\right).\right]$ 
extinção. Devido a isso, um dos mecanismos que aumenta a capacidade de extinção da microestrutura é a adição de agentes opacificadores [23, 25]. Esses agentes possuem alta capacidade de absorção de fótons de radiação térmica nas faixas de interesse, isto é, para as faixas de comprimento de onda de fótons localizados próximos do pico de emissão nas temperaturas de uso dos isolantes (equação M). Dessa forma, para selecionar o melhor agente opacificante para a aplicação em questão, além da temperatura de trabalho do material, também se deve conhecer a capacidade de extinção da microestrutura do material da matriz, por exemplo, alumina, sílica, magnésia, etc. Assim, sabe-se qual a matriz do isolante é mais limitada na sua capacidade de extinção. Por exemplo, observando a Fig. 6, nota-se que a magnésia densa $(\mathrm{MgO})$ possui uma capacidade de absorção de radiação muito reduzida para fótons que possuam comprimento de onda abaixo de aproximadamente $8 \mu \mathrm{m}$. Sendo assim, fótons na faixa de $8 \mu \mathrm{m}$ a $0,5 \mu \mathrm{m}$ devem ser extintos, seja por meio de espalhamento e/ou opacificação. Para que isto ocorra deve-se adicionar, juntamente com a porosidade, materiais que apresentem um alto coeficiente volumétrico de extinção e, se possível, baixa condutividade térmica. Assim, para selecionar o agente opacificante, deve-se obter seu espectro de extinção (na faixa de interesse) e este deve ser normalizado em relação ao volume de amostra que foi analisada. Para levantar o espectro de extinção do material de interesse, basta obter o espectro de transmissão de uma amostra de massa e densidade conhecidas. A equação $\mathrm{N}$ é utilizada com esta finalidade [23].

$$
\beta_{\text {ext }}(\lambda)=\frac{-\ln [\tau(\lambda)]}{\rho . t}
$$

sendo $\beta_{\text {ext }}(\lambda)$ o coeficiente de extinção espectral $\left(\mathrm{m}^{2} \mathrm{~kg}^{-1}\right)$; $\tau$ é a transmitância (\%) da amostra e, portanto, é função de $\lambda ; \rho$ é a densidade do material $\left(\mathrm{kg} / \mathrm{m}^{3}\right)$ e $\mathrm{t}$ é a espessura da amostra (m). Portanto, por meio dos valores de transmitância, espessura e densidade conhecidas, podem-se comparar diversos materiais no que concerne ao seu grau de opacificação.

A Fig. 12 apresenta $\beta_{\text {ext }}$ em função de $\lambda$ para vários materiais cerâmicos opacificadores, adicionados em uma concentração de $20 \%$ em peso, numa matriz de sílica pirolisada pura. A eficiência da opacificação não é apenas função da densidade e da espessura da amostra de material, mas também do tamanho de partícula do opacificador, uma vez que este fenômeno é mais intenso quando a diferença entre o índice de refração da matriz e do agente opacificante é grande. Dessa forma, a partícula de opacificante atua também como um centro de espalhamento de fótons (ver equação J), cujo efeito pode ser observado na Fig. 13.

Outro fator a ser considerado para a seleção de materiais opacificadores é a sua temperatura de utilização. A Tabela I apresenta a temperatura máxima de trabalho dos materiais apresentados na Fig. 12.

Opacificadores são mais adequados quanto maior for a porosidade do material isolante. Para microestruturas com baixíssima condução através do sólido a contribuição da

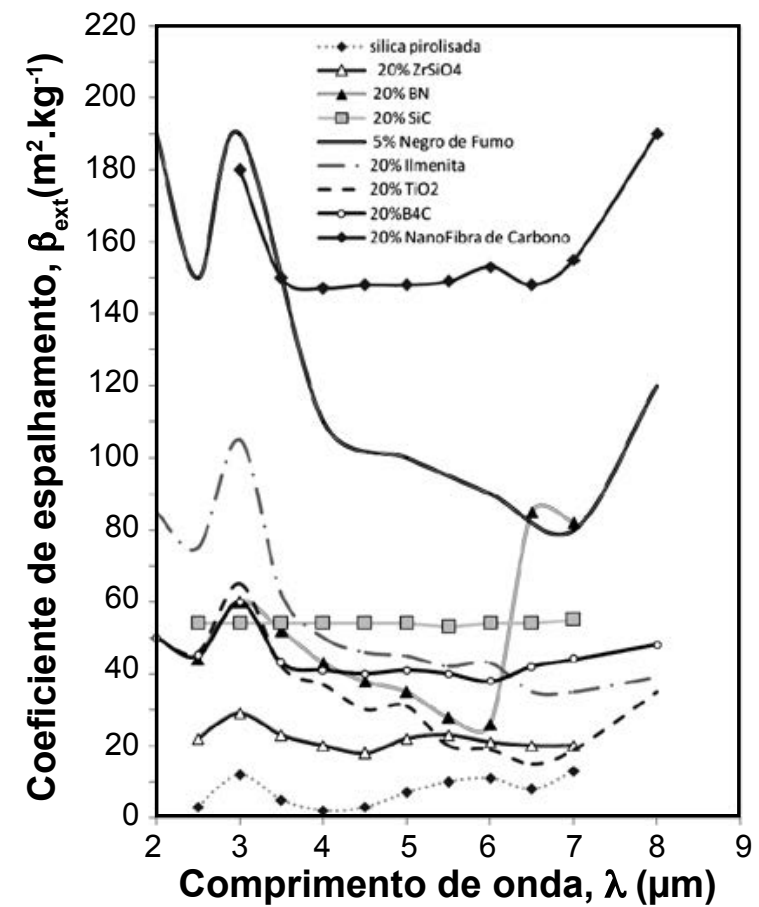

Figura 12: Coeficiente de extinção espectral $\beta_{\text {ext }}(\lambda)$ de vários materiais cerâmicos opacificadores, adicionados à sílica pirolisada, medido à temperatura ambiente [23, 26, 27, 29].

[Figure 12: Spectral extinction coefficient $\beta_{\text {ext }}(\lambda)$ of various ceramic opacifier materials added to fume silica, measured at room temperature [23, 26, 27, 29].]

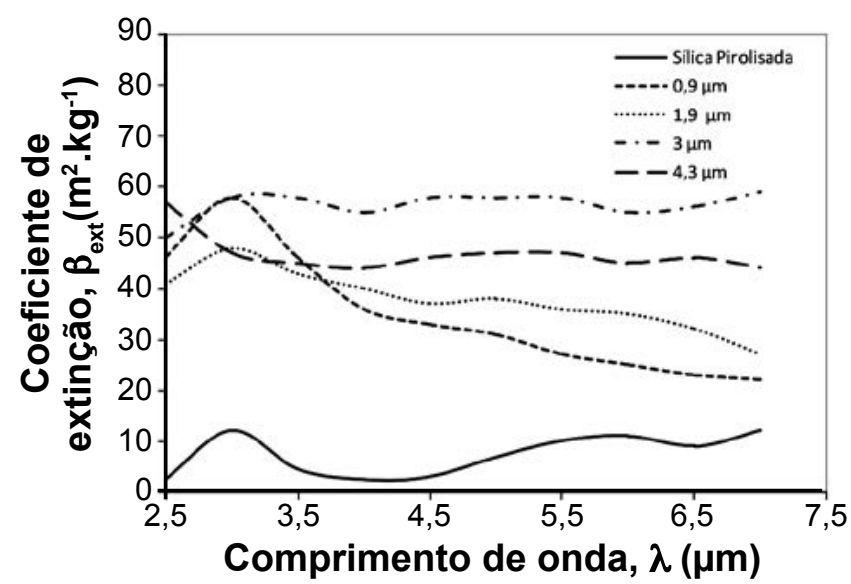

Figura 13: Coeficiente de extinção espectral para 25\%p de SiC adicionado em sílica pirolisada em função do tamanho de partícula, na faixa 0,9-4,3 $\mu \mathrm{m}$, medido à temperatura ambiente [23].

[Figure 13: Spectral extinction coefficient for fume silica with addition of $25 \mathrm{wt} . \%$ of SiC as a function of the particle size (0.9-4.3 $\mu \mathrm{m})$, measured at room temperature [23].]

radiação torna-se mais importante, isto é, à proporção que a radiação assume na condutividade total do material tornase elevada [41, 42]. Este fato é melhor descrito na seção de acoplamento entre condução e radiação.

Outra característica importante para seleção de materiais opacificadores é a sua condutividade térmica por fônons, isto é, $\mathrm{K}_{\text {cond }}$. Como mostrado acima, o efeito que se busca em materiais opacificadores é a redução da condutividade 
Tabela I - Temperatura máxima (Tmáx) de trabalho de diversos materiais opacificadores [24].

[Table I - Maximum working temperature (Tmax) of various opacifier materials [24].]

\begin{tabular}{cccccccc}
\hline Material & $\mathrm{ZrSiO}_{4}$ & $B N$ & $B_{4} \mathrm{C}$ & Ilmenita & $\mathrm{SiC}$ & Nanofibra de C & $\mathrm{TiO}_{2}$ \\
\hline Tmáx $\left({ }^{\circ} \mathrm{C}\right)$ & 1500 & 1000 & $2700 *$ & 1300 & 1600 & 500 & 1800 \\
\hline
\end{tabular}

*Em atmosfera não oxidante

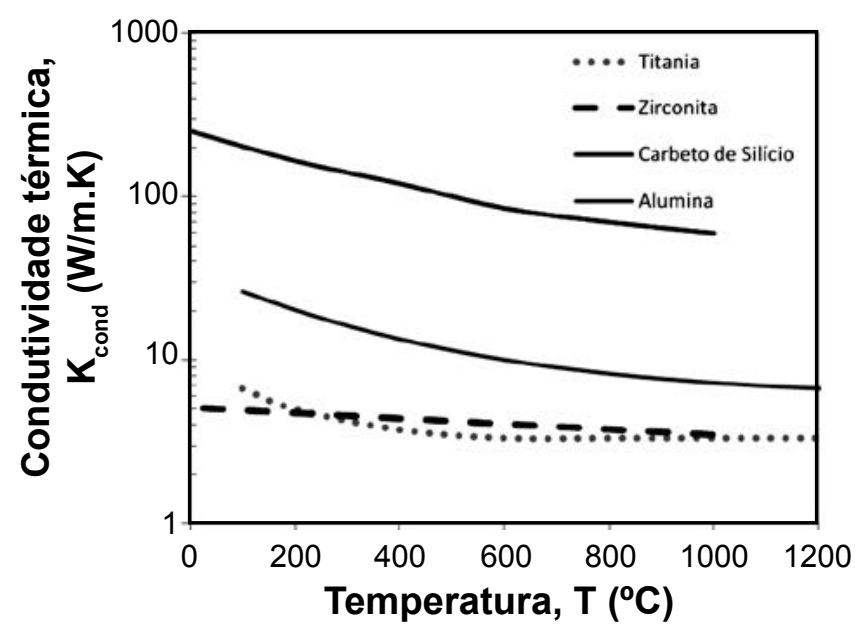

Figura 14: Condutividade térmica $\mathrm{K}_{\text {cond }}$ de alguns materiais opacificadores: titânia $\left(\mathrm{TiO}_{2}\right)$, zirconita $\left(\mathrm{ZrSiO}_{4}\right)$ e carbeto de silício (SiC) [24, 28, 39].

[Figure 14: Thermal conductivity $K_{\text {cond }}$ of various opacifier materials: titânia $\left(\mathrm{TiO}_{2}\right)$, zircon $\left(\mathrm{ZrSiO}_{4}\right)$ and silicon carbide $(\mathrm{SiC})$ [24, 28, 39].]

térmica por radiação, todavia, se a condutividade térmica do material for muito elevada, isto pode aumentar a condutividade total do material ao invés de reduzi-la. A Fig. 14 mostra a condutividade térmica, $\mathrm{K}_{\text {cond }}$, de três materiais opacificadores em função da temperatura. Como pode ser observado, a titânia e a zirconita possuem condutividade térmica baixa, comparada à alumina. Entretanto, o carbeto de silício possui condutividade por fônons bastante elevada.

Assim, pode-se concluir que por meio da porosidade, a qual eleva o coeficiente de espalhamento, $\beta_{\mathrm{s}}$, e na da presença de agentes opacificantes de infravermelho adequados, os quais elevam o coeficiente espectral de absorção, $\beta_{\mathrm{a}}$, é possível aumentar o coeficiente de extinção médio do material, $\beta *$, e desse modo, reduzir a transferência de energia por radiação, fato de extrema importância para isolantes térmicos utilizados em altas temperaturas.

\section{Acoplamento condução-radiação}

Existem teorias de acoplamento, isto é, associação dos mecanismos de condução e de radiação para os materiais, que consideram a interferência destes no que concerne o fluxo de calor através do material e, portanto, na condutividade térmica. Para tanto se utiliza de um parâmetro adimensional que relaciona as equações de condução térmica e de radiação chamado de $\mathrm{N}_{1}$, apresentado na equação $O$ [16].

$$
\mathrm{N}_{1}=\frac{\mathrm{K}_{\text {cond }} \beta^{*}}{4 \cdot \sigma \cdot \mathrm{T}_{1}^{3}}
$$

sendo $\mathrm{T}_{1}$ a temperatura da face quente do material e $\mathrm{K}_{\text {cond }}$ a condutividade térmica da matriz do material, calculada pelas equações $\mathrm{B}$ ou $\mathrm{C}$, as quais simulam a condutividade térmica quando existe porosidade na microestrutura. $\mathrm{Na}$ equação $\mathrm{O}$ observa-se que $\mathrm{N}_{1}$ é apenas uma relação entre a condutividade do material sólido e a condutividade por radiação. Quanto $\mathrm{N}_{1}$ tende à zero, a contribuição da radiação é dominante, e quando tende a infinito, a contribuição da condução prevalece.

As teorias de acoplamento levam em consideração outro parâmetro muito importante, que é a espessura ótica do material $\beta_{t}$, que é função da espessura do material (t) e de seu coeficiente de extinção médio $\beta^{*}$, dada pela equação $\mathrm{P}$ [17]:

$$
\beta_{\mathrm{t}}=\beta^{*} . \mathrm{t}
$$

na qual $\beta_{\mathrm{t}}$ é um número adimensional, pois $\beta^{*}$ é expresso em unidade recíproca do metro e quantifica a opacidade de uma determinada porção de material. Valores de $\beta_{\mathrm{t}}$ muito próximos de zero indicam transparência e superiores à unidade indicam opacidade. Utilizando-se o parâmetro $\mathrm{N}_{1}$ e a espessura ótica $\beta_{\mathrm{t}}$, a teoria de acoplamento entre condução e radiação pode descrever, por exemplo, o perfil de temperatura ao longo da espessura do material. A Fig. 15 mostra a temperatura relativa $\left(\theta=T / T_{1}\right)$ em função da espessura ótica e de $\mathrm{N}_{1}$, sendo $\mathrm{T}_{1}$ a temperatura da face quente $\mathrm{e} \mathrm{T}$ a temperatura em qualquer posição na espessura do material, por isso a temperatura relativa na face quente é igual à $1\left(\theta=\mathrm{T}_{1} / \mathrm{T}_{1}=1\right)$. Isto pode ser interpretado como sendo o perfil de temperatura de um material em função de sua espessura ótica.

Como pode ser observado, quanto menor sua espessura ótica, maior será a temperatura na "face fria" do material e quanto menor o valor de $\mathrm{N}_{1}$ (maior a contribuição da radiação), maior a temperatura na face para uma mesma espessura ótica. A condutividade térmica é que define a temperatura da face fria em relação à quente, portanto quanto maior a primeira, maior a condutividade térmica.

Para a melhor compreensão do que foi dito acima, basta observar as retas A e B na Fig. 15. A reta A representa a face fria de um material que possua $\beta_{\mathrm{t}}$ igual a $0,6 \mathrm{e}$, as intersecções com as curvas referentes a diferentes valores de $\mathrm{N}_{1}$, indicam a temperatura relativa na face exterior do material $\mathrm{T}$. $\mathrm{O}$ mesmo raciocínio é válido para a reta $\mathrm{B}, \operatorname{com} \beta_{\mathrm{t}}$ igual à 0,8 . Pode-se notar que quanto maior $\beta_{\mathrm{t}}$, menor a temperatura na 


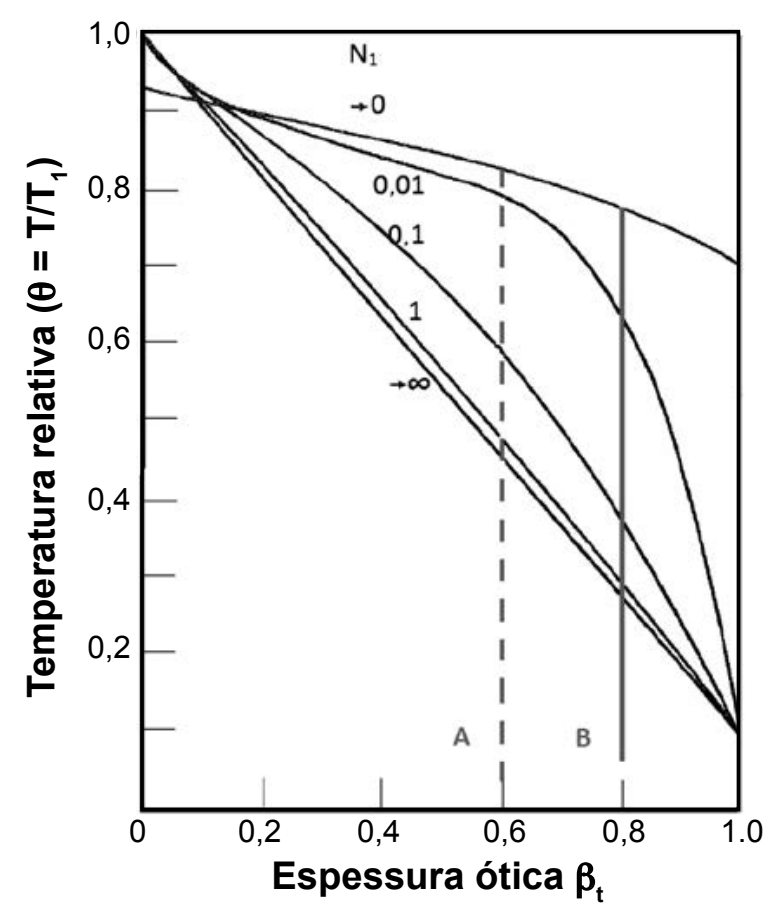

Figura 15: Temperatura relativa em função da espessura ótica (adaptado de [16]).

[Figure 15: Relative temperature as a function of the optical thickness (adapted from [16]).]

face fria, para quaisquer valores que $\mathrm{N}_{1}$ eventualmente possa assumir. Este fato, mais uma vez, demonstra a importância em se aumentar a capacidade de extinção de radiação térmica em microestruturas com propósito de isolamento, tal como em estruturas porosas. Ao se observar a Fig. 15, nota-se que, ao se fixar a espessura ótica $\beta_{\mathrm{t}}$, o valor de $\mathrm{K}_{\text {cond }}$ também está fixo, uma vez que ambos dependem da composição e microestrutura do material em questão. Dessa forma, para uma espessura ótica fixa, o valor de $\mathrm{N}_{1}$ só pode ser mudado caso a temperatura da face quente $\mathrm{T}_{1}$ for alterada (ver equação O). Portanto, quando se observa as retas $\mathrm{A}$ e B na Fig. 15 nota-se que a mudança dos valores de $\mathrm{N}_{1}$ está relacionada à elevação da temperatura da face quente $\mathrm{T}_{1}, \mathrm{o}$ que mostra um resultado esperado, que indica que quanto maior a temperatura da face quente, maior a temperatura relativa à uma determinada espessura ótica $\beta_{\mathrm{t}}$.

Outro modo de entender esse conceito foi proposto por Einstein e este é descrito como o modelo de aditividade, como mostrado na equação Q [16]:

$$
\frac{\mathrm{q}}{\mathrm{\sigma T}_{1}{ }^{4}}=\frac{4 \mathrm{~N}_{1}\left(1-\theta_{2}\right)}{\beta_{\mathrm{t}}}+\frac{\left(1-\theta_{2}{ }^{4}\right)}{\frac{3 \beta_{\mathrm{t}}}{4}+\frac{1}{\varepsilon_{1}}+\frac{1}{\varepsilon_{2}}-1}
$$

sendo q o fluxo total de energia $\left(\mathrm{W} / \mathrm{m}^{2}\right), \mathrm{T}_{1}$ a temperatura da face quente, $\theta_{2}$ a relação entre $\mathrm{T}_{1}$ e $\mathrm{T}_{2}\left(\theta_{2}=\mathrm{T}_{2} / \mathrm{T}_{1}\right)$, na qual $\mathrm{T}_{2}$ é a temperatura da face fria, e $\varepsilon_{1}$ e $\varepsilon_{2}$ as emissividades da face quente e fria, respectivamente.

A Fig. 16 apresenta os resultados calculados por meio da equação acima:

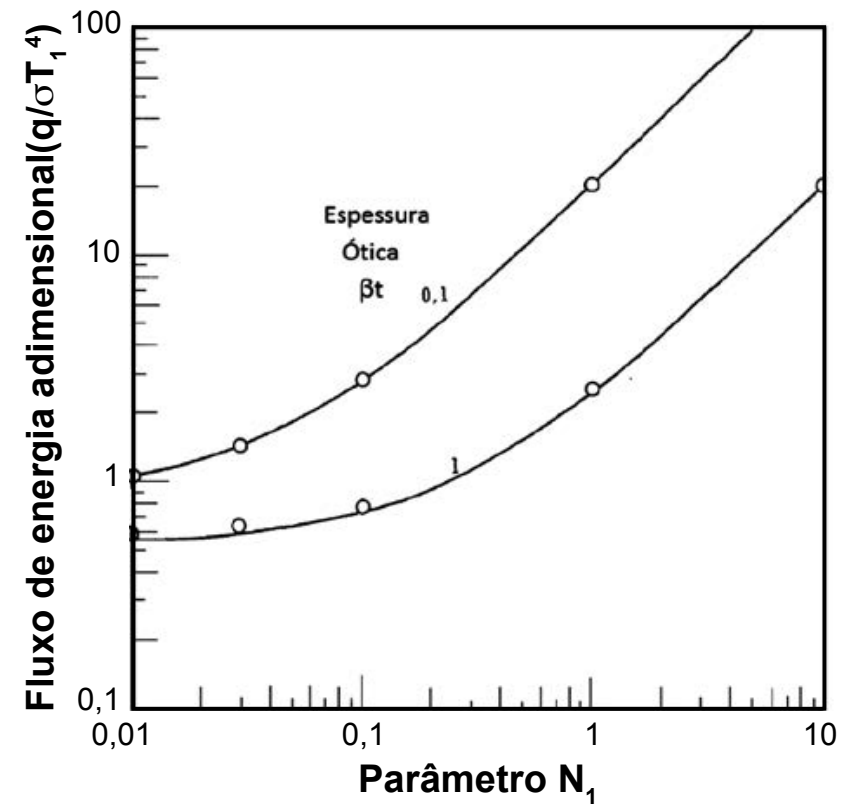

Figura 16 : Fluxo de energia adimensional em função do parametro $\mathrm{N}_{1}$ e da espessura ótica, $\beta_{\mathrm{t}}$ (adaptado de [16]).

[Figure 16: Adimensional energy flux as a function of $N_{1}$ parameter and the optical thickness, $\beta_{t}$ (adapted from [16]).]

A Fig. 16 corrobora as observações apresentadas pela Fig. 15, e mostra os efeitos de $\mathrm{N}_{1}$ e $\beta_{\mathrm{t}}$ com relação ao fluxo de energia total através do material, normalizado pelo fluxo energético causado pela emissão de um corpo negro à temperatura $\mathrm{T}_{1}\left(\sigma \mathrm{T}_{1}\right)$. Novamente, observa-se que o aumento da espessura ótica é responsável pela redução do fluxo energético através do material.

\section{Convecção}

Isolantes porosos possuem grande parte de sua porosidade aberta, isto é, apresentam conexões entre os poros do interior do corpo e a superfície deste. Desta forma, outro processo de transferência térmica acaba ocorrendo nesses materiais, que é a convecção do ar entre os poros do material. A contribuição desse tipo de transferência de energia térmica é função de diversos parâmetros, entre eles, a permeabilidade do material [8]. É importante diferenciar entre os dois tipos de contribuição para a condutividade efetiva que a convecção pode propiciar: 1) deve ser considerada a convecção dentro de um único poro fechado, uma vez que o gás passa a circular dentro do poro e transfere energia desse modo; 2) a convecção entre os poros conectados. O primeiro caso, de convecção dentro do poro, foi analisado por Ashby [9], o qual constatou que este deveria ter um diâmetro superior à $10 \mathrm{~mm}$ para que haja esse tipo de efeito. Outros autores apontam para valores inferiores, como $4 \mathrm{~mm}$ [7]. De qualquer forma, esses dados revelam que poros micrométricos não possuem esse tipo de contribuição. O segundo caso é bem mais complexo e sua análise requer o conhecimento de diversas propriedades do material sólido e do fluido que permeia os poros, geralmente o ar. Dessa forma, a equação 
$\mathrm{R}$ descreve essa contribuição [8]:

$$
\mathrm{K}_{\text {conv }}=\mathrm{K}_{\mathrm{o}} \cdot(\mathrm{Nu}-1)
$$

sendo $\mathrm{K}_{\mathrm{o}}$ a condutividade do gás na ausência de convecção e $\mathrm{Nu}$ o número de Nussel. $\mathrm{O}$ cálculo de $\mathrm{Nu}$ não é trivial e diversas formas foram propostas na literatura [9] para realizá-lo. No entanto, sabe-se que o valor de $\mathrm{Nu}$ é função da permeabilidade do material, que está associada ao número de Rayleigh Ra, como pode ser observado no apêndice B.

A Tabela II mostra a relação entre Ra e o número de Nussel.

Tabela II - Dependência do número de Nussel com o de Rayleigh [8].

[Table II - Nussel and Rayleigh's numbers relationship [8].]

\begin{tabular}{cc}
\hline Número de Rayleigh, $R a$ & Número de Nussel, Nu \\
\hline$<40$ & 1 \\
$40-400$ & $0,4 \cdot \mathrm{Ra}^{1 / 2}-1,5$ \\
$400-1000$ & $0,17 \cdot \mathrm{Ra}^{1 / 2}+2,8$ \\
\hline
\end{tabular}

A permeabilidade de um material é uma medida macroscópica da facilidade com que um fluido passa através de um corpo. Essa propriedade foi descrita por Darcy, o qual definiu um parâmetro que se chama permeabilidade Darciana, $\eta_{1}$. Mais recentemente, Forchheimer mostrou que os efeitos inerciais devem ser levados em conta e isto levou à introdução de outro parâmetro para descrever esta propriedade, a permeabilidade não Darciana, $\eta_{2}$ [9]. Em relação às cerâmicas porosas, a permeabilidade Darciana $\eta_{1}$ e a não Darciana $\eta_{2}$ podem ser descritas pelas equações $S$ e $\mathrm{T}[9]$, respectivamente:

$$
\begin{aligned}
& \mathrm{n}_{1}=0,015 \cdot P \cdot \mathrm{d}_{\mathrm{e}}{ }^{2} \\
& \mathrm{n}_{2}=0,015 \cdot P \cdot \cdot^{2} \mathrm{~d}_{\mathrm{e}}
\end{aligned}
$$

sendo $\mathrm{P}$ a porosidade $(\%)$ e $\mathrm{d}_{\mathrm{e}} \mathrm{o}$ diâmetro equivalente $(\mu \mathrm{m})$, o qual pode ser calculado pela equação $U$, mostrada abaixo [9]:

$$
d_{e}=\frac{P \cdot D_{p}}{1,5 \cdot(1-P)}
$$

sendo $\mathrm{D}_{\mathrm{p}}$ o diâmetro médio $(\mu \mathrm{m})$ dos poros do material.

Como pode ser visto nas equações $\mathrm{S}$ e $\mathrm{T}$, dada uma porosidade fixa, a permeabilidade pode ser reduzida por meio da diminuição do tamanho de poros. Entretanto, deve-se notar que as relações apresentadas na Tabela II não levam em conta a permeabilidade não Darciana para Ra (ver apêndice B). A literatura mostra que para cerâmicas produzidas pelo método de espumação direta, microestruturas com poros abaixo de $50 \mu \mathrm{m}$ possuem permeabilidade baixas, as quais por sua vez induzem uma reduzida contribuição da convecção interna para a condutividade térmica do material $[8,9]$.

\section{Produtos atuais}

A maioria dos isolantes cerâmicos encontrados no mercado atualmente são composições de alumina e sílica. A Tabela III mostra as faixas de valores para a condutividade térmica de isolantes cerâmicos de acordo com a sua geometria (tijolo, manta, etc.) e parâmetros da microestrutura (tamanho de poro e diâmetro de fibra) na faixa de temperaturas entre $800{ }^{\circ} \mathrm{C}$ e $1200{ }^{\circ} \mathrm{C}[30,31,34-36,40]$.

Tabela III - Condutividade térmica e parâmetros

\begin{tabular}{|c|c|c|c|}
\hline $\begin{array}{c}\text { Tipo de } \\
\text { Material }\end{array}$ & $\begin{array}{l}\text { Faixa de } \\
\text { Porosidade } \\
\text { (\%) }\end{array}$ & $\begin{array}{l}\text { Faixa de } \\
\text { Tamanho } \\
\text { de Poros }\end{array}$ & $\begin{array}{c}\text { Condutividade } \\
\text { Térmica } \\
(\mathrm{W} / \mathrm{m} . \mathrm{K})\end{array}$ \\
\hline Tijolos & $50-85$ & $\begin{array}{l}\text { Centenas } \\
\text { de mícrons } \\
\text { até } \\
\text { milímetros }\end{array}$ & $0,2-1,5$ \\
\hline $\begin{array}{l}\text { Mantas } \\
\text { Cerâmicas } \\
\text { Fibrosas }\end{array}$ & $85-98$ & $\begin{array}{c}\text { Diâmetro } \\
\text { da fibra: } \\
5 \text { até } 30 \\
\mu \mathrm{m}\end{array}$ & $0,08-0,4$ \\
\hline Microporosos & $>90$ & $<0,1 \mu \mathrm{m}$ & $<0,1$ \\
\hline
\end{tabular}
microestruturais de isolantes comerciais.

[Table III - Thermal conductivity and microstructural parameters for commercial insulating materials.]

Nas últimas décadas, o aparecimento de isolantes constituídos por fibras cerâmicas teve um efeito importante no projeto de isolamento de fornos. Este tipo de material, na forma de uma manta composta de inúmeras fibras cerâmicas emaranhadas, é fácil de instalar e oferece grande resistência ao fluxo de calor. Esses materiais podem apresentar condutividades térmicas muito reduzidas, na faixa de 0,08 a $0,4 \mathrm{~W} / \mathrm{m}-\mathrm{K}$ entre 500 e $1000{ }^{\circ} \mathrm{C}$. Esses valores são considerados de muito baixa condutividade térmica e estão associados à altíssima porosidade apresentada por estes materiais. Mantas dessa natureza são geralmente aplicadas na "face fria" de fornos, isto é, na parede exterior, mesmo porque estes materiais são muito sensíveis à pressão, pois quando mantidas sob compressão, apresentam elevação na condutividade devido ao aumento dos pontos de contato entre as fibras [38], o que impede sua utilização em aplicações que exigem carregamento mecânico. Entretanto, a produção de materiais cerâmicos fibrosos tem sido associada à problemas de saúde. Esse fato tem motivado o desenvolvimento de isolantes substitutos e não fibrosos [37]. No entanto, para atingir valores de condutividade térmica próxima a das mantas cerâmicas é necessário aprimorar a microestrutura dos isolantes porosos levando em consideração todos os mecanismos de transferência de calor, apresentados nas seções anteriores.

Outro tipo de isolamento utilizado industrialmente é 
aquele que usa pós refratários não sinterizados. Dessa forma, a resistência térmica existente entre as partículas do pó é grande, pois não há um contato íntimo entre as partículas como há entre grãos sinterizados. Esse fenômeno é explicado pelo baixo valor de $\mathrm{M}$ nesses materiais, presente na equação C. Esses materiais são constituídos em grande parte de alguma forma de $\mathrm{SiO}_{2}$, seja partículas de sílica fundida, sílica pirolisada ou mesmo partículas de aerogel juntamente com ligantes, como sílica coloidal e ligantes orgânicos. Adicionalmente, utilizam-se nesses materiais vários agentes opacificadores para infravermelho como: titânia, óxido de ferro, ilmenita, carbeto de silício, zirconita e outros [32, 33]. Entretanto, esse tipo de material tem sua temperatura de uso limitada devido à elevada sinterabilidade do material em temperaturas superiores a $1100{ }^{\circ} \mathrm{C} \mathrm{e}$, mesmo em materiais que possuam menos sílica, caso estes sejam utilizados próximos à sua temperatura de sinterização, a estrutura desses materiais é alterada. Assim como as mantas de fibras cerâmicas, materiais particulados não podem ser submetidos à cargas mecânicas significativas.

\section{CONCLUSÕES}

O desempenho térmico de isolantes cerâmicos pode ser otimizado através da compreensão dos mecanismos que determinam a condutividade térmica desses materiais. A presente revisão permite estabelecer alguns pontos decisivos: 1- A porosidade total de uma microestrutura, juntamente com a presença de trincas e defeitos na porção sólida do material, define a redução da condutividade térmica em relação ao sólido completamente denso. Quanto maior a porosidade total e maior a concentração de defeitos na porção sólida, menor a condutividade térmica, entretanto, esse fato deve ser acoplado à análise da resistência mecânica do material, a qual decai mediante a presença dos mesmos fatores. 2- O tamanho dos poros, juntamente com a presença de materiais opacificadores, define a capacidade da microestrutura em extinguir a radiação térmica e, portanto, reduzem a contribuição da radiação na condutividade térmica do material. A faixa de tamanho de poro mais efetiva para o espalhamento da radiação térmica está entre 0,5 e $4 \mu \mathrm{m}$ e o opacificador mais adequado deve ser escolhido mediante a análise de três fatores: sua capacidade de extinção de radiação térmica, sua condutividade por fônons $\left(\mathrm{K}_{\text {cond }}\right)$ e a sua estabilidade térmica. 3- A redução da permeabilidade da microestrutura do material promove uma redução da contribuição da convecção de gás dentro deste. Materiais que possuam poros com diâmetro abaixo de $50 \mu \mathrm{m}$ apresentam baixíssima contribuição da convecção para o processo de transferência de calor. Portanto, a porosidade total, a capacidade de extinção e a permeabilidade são os principais parâmetros de projeto para a geração de microestruturas otimizadas utilizadas em isolamento térmico. Por meio da utilização desses parâmetros, e aliando conceitos de resistência mecânica, produtores de isolantes podem definir a melhor microestrutura para seus produtos para cada faixa de temperatura de utilização.

\section{AGRADECIMENTOS}

À CAPES e ao CNPq pelo apoio dado a esta pesquisa.

\section{REFERÊNCIAS}

[1] R. A. Kerr, Science 329 (2010) 780.

[2] H. Crane, E. Kinderman, R. Malhotra, A Cubic Mile of Oil: Realities and Options for Averting the Looming Global Energy Crisis, $1^{\text {a }}$ Ed., Oxford Univ. Press, Oxford, Inglaterra (2010) 233-261.

[3] E. Worrell, C. Galitsky, Energy Efficiency Improvement and Cost Saving Opportunities for Petroleum Refineries: An Energy Star Guide for Energy and Plant Managers, LBNL56183, Environmental Energy Techn. Div., Lawrence Berkeley National Laboratory, EUA (2005).

[4] Energetics Inc., Energy Loss Reduction and Recovery in Industrial Energy Systems, Technology Roadmap, U.S. Department of Energy, Office of Energy Efficiency and Renewable Energy, EUA (2004).

[5] M. F. Ashby, Materials Selection in Mechanical Design, $3^{\text {a }}$ Ed., Butterworth-Heinemann, Oxford, Inglaterra (2005) 512.

[6] W.D. Kingery, H. K. Bowen, D. R. Uhlmann, Introduction to Ceramics, $2^{\text {nd }}$ Ed., John Wiley \& Sons, New York, EUA (1975) 612-634.

[7] P. G. Colishaw, J. R. G. Evans, J. Mater. Sci. 29 (1994) 486.

[8] E. Litovsky, M. Shapiro, A. Shavit, J. Am. Ceram. Soc. 79 (1996) 1366.

[9] M. Sheffler, P. Colombo, Cellular Ceramics: Structure, Manufacturing, Properties and Applications, $1^{\text {a }}$ Ed., John Wiley, New York, EUA (2005) 313-359.

[10] T. Tritt, Thermal conductivity: theory, properties, and applications, $1^{\text {a }}$ Ed., Kluwer Acad., New York, EUA (2004) 93-102.

[11] M. Kaviany, Principles of Heat Transfer in Porous Media, $2^{\text {nd }}$ Ed., Springer-Verlag, Alemanha (1991) 259-360.

[12] T. Clyne, I. Golosnoy, J. Tan, A. E. Markaki, Phil. Trans. Royal Soc. 354 (2005) 125.

[13] R. H. Perry, D. W. Green, Perry's Chemical Engineers' Handbook, $8^{\mathrm{a}}$ Ed., McGraw Hill, EUA (2007) 2-325 .

[14] E. Litovsky, T. Gambaryan-Roisman, M. Shapiro, A. Shavit, J. Am. Ceram. Soc. 82 (1999) 994.

[15] H. Zhang, X. He, F. He, J. Alloy. Compnd. 469 (2009) 366.

[16] R. Siegel, J. R. Howell, Thermal radiation heat transfer Vol. III: Radiative transfer with absorbing, emitting and scattering media, $1^{a}$ Ed., NASA, Washington, EUA (1973) 241-264.

[17] M. F. Modest, Radiative Heat Transfer, $2^{\text {nd }}$ Ed., Acad. Press, EUA (2003) 61-196.

[18) N. Bogatyreva, J. Phys.: Conf. Ser. 275 (2011) 1.

[19] http://www.lyyn.com/scattering, acessado em 04/2011

[20] H. C. van de Hulst, Light Scattering by small particles, Dover Publ. Inc., New York, EUA (1981) 383-390.

[21] M. W. Barsoum, Fundamentals of ceramics, $2^{\text {nd }}$ Ed., 
IOP, Philadelphia, EUA (1997) 553-580.

[22] http://omlc.ogi.edu/calc/mie_calc.html, acessado em 03/2011.

[23] J. Feng, D. Chen, W. Ni, S. Yang, Z. Hu, J. Non-Cryst. Sol. 356 (2010), 480.

[24] J. F. Shackelford, W. Alexander, CRC Materials Science and Engineering Handbook, $3^{\mathrm{a}}$ Ed. CRC Press, Boca Raton, EUA (2001) Tabela 357.

[25] T. Rhettelbach, J. Säuberlick, S. Korder, J. Fricke, J. Phys. D: Appl. Phys. 28 (1995) 581.

[26] J. Fricke, X. Lu, P. Wang, D. Büttner, U. Heinemann, Int. J. Heat Mass Transfer 35 (1992) 2305.

[27] J. Khun, T. Gleissner, M.C. Arduini-Schuster, S. Korder, J. Fricke, J. Non-Cryst. Sol. 186 (1995) 291.

[28] W. Thurber, J. Mante, Phys. Rev. 139 (1965)1655.

[29] T. Wei, S. Lu, Y. Chang, J. Phys. Chem. 113 (2009) 7424.

[30] V. Gumen, A. ul-Haq, B. Ilyas, A. Maqsood, J. Mat. Eng. Perform. 10 (2001) 475.

[31] B. Zhang, S. Zhao, X. He, S. Du, J. Mater. Sci. Technol. 23 (2007) 860.

[32] K. Abdul-Kader, M. Mortimer, T. Yamamuro, Granular Fibre-Free Microporous Thermal Insulation Material and Method, Patente WO 2006/097668 A1, Inglaterra (21/09/2006).

[33] M. Mortimer, A. Cawley, T. Mathews, Microporous Thermal Insulation Material, Patente WO2005/040063-A1 (06/05/2005).

[34] http://www.bnzmaterials.com/insulating_fire_brick.html, acessado em 02/2011.

[35] http://www.unifrax.com.br/fibra-ceramica.asp, acessado em $02 / 2011$.

[36] http://www.microtherm.uk.com/EXEN/site/index.aspx, acessado em 02/2011.

[37] E. Schlegel, K. Häubler, H. Seifert, Interceram 56 (2007) 336.

[38] A. Maqsood, M. Anis-ur-Rheman, V. Gumen, A. ulHaq, J. Phys. D: Appl. Phys. 33 (2000) 2057.

[39] M. Munro, J. Am. Ceram. Soc. 80 (1997) 1919.

[40] A. M. Papadopoulos, Energy Buildings 37 (2004) 77.

[41] R. Coquard, D. Rochais, D. Baillis, Fire Technol. (2010).

[42] J. P. Holman, Transferência de calor, McGraw-Hill do Brasil, S. Paulo, SP (1983) 639p.

(Rec. 01/08/2011, Rev. 14/10/2011, Ac. 22/10/2011)

\section{Apêndice A - Cálculo de $\boldsymbol{\beta}_{\mathrm{R}}$ e $P_{\mathrm{M}}$}

Os coeficientes de Rosseland e de Planck, como apresentados anteriormente, são formas de calcular um coeficiente de extinção médio $\left(\beta^{*}\right)$. Pode-se compreendêlos como uma forma de atribuir um peso à extinção causada em cada comprimento de onda, relativo ao espectro de emissão de corpo negro de Planck. Dessa forma é possível entender se a extinção é realmente efetiva ou não. Por exemplo, se um material possui alto $\beta_{\text {ext }}$ no comprimento de onda de $10 \mu \mathrm{m}$, isso pouco influenciará $\beta^{*}$ caso a temperatura em questão seja elevada, pois se sabe que o pico de emissão não se encontra nessa faixa. Para que $\beta^{*}$ seja alto, o coeficiente de extinção espectral $\left(\beta_{\text {ext }}\right)$ deve ser elevado nos comprimentos de onda de interesse, dependendo da temperatura de serviço.

A equação A1 é utilizada para o cálculo do coeficiente de Rosseland [16-18]:

$$
\beta_{\mathrm{R}}^{-1}=\frac{\int \beta_{\mathrm{ext}}{ }^{-1} \frac{\mathrm{dB}(\mathrm{T}) \mathrm{d} \lambda}{\mathrm{dT}}}{\int \frac{\mathrm{dB}(\mathrm{T}) \mathrm{d} \lambda}{\mathrm{dT}}}
$$

Como pode ser observado, o coeficiente de Rosseland é calculado utilizando a primeira derivada da equação de emissão de Planck e integrada no espectro de comprimentos de onda. A primeira derivada da equação de Planck pode ser observada na equação A2 [18]:

$$
\frac{d B}{d T}(T)=\frac{2 h^{2} c^{2}}{k T^{2} \lambda^{4}} \cdot \frac{e^{\frac{h c}{k T \lambda}}}{e^{\frac{h c}{k T \lambda}}-1}
$$

O coeficiente de extinção de Planck pode ser calculado por meio da equação A3. Como pode ser observado, este coeficiente utiliza a equação de Planck diretamente em seus cálculos $[16,18]$ :

$$
\mathrm{P}_{\mathrm{M}}=\frac{\int \beta_{\text {ext }} \mathrm{B}(\mathrm{T}) \mathrm{d} \lambda}{\int \mathrm{B}(\mathrm{T}) \mathrm{d} \lambda}
$$

Um ponto que deve ser destacado é que, como pode ser notada nas equações A1 e A3, a unidade dos coeficientes de Rosseland e de Planck será a mesma do coeficiente de extinção espectral $\beta_{\text {ext }}$.

\section{Apêndice B - Cálculo de Ra}

$\mathrm{O}$ número de Rayleigh pode ser calculado através da seguinte equação B1 [8]:

$$
\mathrm{Ra}=\frac{\mathrm{g} \alpha \cdot \mathrm{L}_{\mathrm{o}} \eta_{1}{ }^{2} \mathrm{C}_{\mathrm{p}} \cdot \Delta \mathrm{T}}{\mu \cdot \mathrm{K}_{0}}
$$

Sendo $\mathrm{g}$ a aceleração da gravidade $\left(\mathrm{m}^{2} / \mathrm{s}\right), \alpha$ o coeficiente de expansão térmica do gás $\left({ }^{\circ} \mathrm{C}^{-1}\right), \mathrm{L}_{\mathrm{o}}$ a espessura do material poroso $(\mathrm{m}), \eta_{1}$ a permeabilidade Darciana $\left(\mathrm{m}^{2}\right), \mathrm{C}_{\mathrm{p}}$ o calor específico do gás $\left(\mathrm{J} / \mathrm{kg}^{-1} \mathrm{~K}^{-1}\right), \Delta \mathrm{T}$ a diferença de temperatura entre as faces do material $\left({ }^{\circ} \mathrm{C}\right), \mu$ a viscosidade dinâmica do gás (Pa.s) e $\mathrm{K}_{0}$ a condutividade do gás na ausência de convecção (W/mK). 